\title{
Body Awareness as an Important Target in Multidisciplinary Chronic Pain Treatment
}

Citation for published version (APA):

van der Maas, L. C. C., Köke, A., Bosscher, R. J., Twisk, J. W. R., Janssen, T. W. J., \& Peters, M. (2016). Body Awareness as an Important Target in Multidisciplinary Chronic Pain Treatment: Mediation and Subgroup Analyses. Clinical Journal of Pain, 32(9), 763-772.

https://doi.org/10.1097/AJP.0000000000000320

Document status and date:

Published: 01/09/2016

DOI:

10.1097/AJP.0000000000000320

Document Version:

Publisher's PDF, also known as Version of record

Document license:

Taverne

Please check the document version of this publication:

- A submitted manuscript is the version of the article upon submission and before peer-review. There can be important differences between the submitted version and the official published version of record.

People interested in the research are advised to contact the author for the final version of the publication, or visit the DOI to the publisher's website.

- The final author version and the galley proof are versions of the publication after peer review.

- The final published version features the final layout of the paper including the volume, issue and page numbers.

Link to publication

\footnotetext{
General rights rights.

- You may freely distribute the URL identifying the publication in the public portal. please follow below link for the End User Agreement:

www.umlib.nl/taverne-license

Take down policy

If you believe that this document breaches copyright please contact us at:

repository@maastrichtuniversity.nl

providing details and we will investigate your claim.
}

Copyright and moral rights for the publications made accessible in the public portal are retained by the authors and/or other copyright owners and it is a condition of accessing publications that users recognise and abide by the legal requirements associated with these

- Users may download and print one copy of any publication from the public portal for the purpose of private study or research.

- You may not further distribute the material or use it for any profit-making activity or commercial gain

If the publication is distributed under the terms of Article $25 \mathrm{fa}$ of the Dutch Copyright Act, indicated by the "Taverne" license above, 


\title{
Body Awareness as an Important Target in Multidisciplinary Chronic Pain Treatment
}

\section{Mediation and Subgroup Analyses}

\author{
Lia C.C. van der Maas, MSc, PhD, *†ई Albère Köke, PhD,\| \\ Ruud J. Bosscher, PhD, Jos W.R. Twisk, PhD,\#** \\ Thomas W.J. Janssen, PhD, $\$$ and Madelon Peters, PhD $\dagger \dagger$
}

\begin{abstract}
Background: The results of a recently performed randomized clinical trial showed that the effect of a multidisciplinary treatment of chronic pain patients on body awareness (BA), catastrophizing, and depression was improved by adding psychomotor therapy (PMT), an intervention targeting BA. No significant effects were found on quality of life and disability. The present follow-up study aimed to explore the relationship between improvements in BA and multidisciplinary chronic pain rehabilitation treatment outcome across treatment conditions and the possible mediating effect of BA between treatment conditions. Furthermore, the hypothesis that patients with low BA benefit more from PMT was investigated.
\end{abstract}

Methods: In total, 94 patients with chronic pain participated in a randomized clinical trial comparing multidisciplinary treatment as usual (TAU) with TAU plus PMT. Outcome variables were healthrelated quality of life, disability, and depression. Self-efficacy and catastrophizing were the process variables of treatment and the potential mediating factors in the relationship between BA and the outcome variables. The data were analyzed by linear mixed-model analysis.

Results: Improvements in BA were related to improvements in all outcome variables across treatment conditions. The relationships were partly mediated by self-efficacy, catastrophizing, or both. In the regression model with depression as the outcome variable, the regression coefficient of treatment (ie, PMT vs. TAU) decreased by $34 \%$ and became nonsignificant when BA was added as a potential mediator. Patients with low BA seemed to benefit more from PMT than patients with high BA, especially on depression, BA, and catastrophizing.

Conclusions: BA might be an important target of treatment to improve the multidisciplinary treatment outcome in chronic pain patients. Furthermore, PMT is an intervention that seems to provide its benefits through improving BA and may be especially beneficial for patients with low BA.

Received for publication April 8, 2015; revised November 24, 2015; accepted October 23, 2015.

From the *Human Movement and Education Division; 9 Department of Human Movement, Health and Well-being, University of Applied Sciences Windesheim, Zwolle; $†$ Reade, Centre of Rehabilitation and Rheumatology; \$Amsterdam Rehabilitation Research Center, Reade; \$Move Research Institute Amsterdam, Faculty of Human Movement Sciences; **Department of Health Sciences, VU University; \#Department of Epidemiology and Biostatistics, VU Medical Centre, Amsterdam; $\|$ Adelante Expertise Centre Pain Rehabilitation, Hoensbroek; and $\dagger \dagger$ Department of Clinical Psychological Science, Maastricht University, Maastricht, The Netherlands.

The authors declare no conflict of interest

Reprints: Lia C.C. van der Maas, MSc, PhD, Human Movement and Education Division, University of Applied Sciences Windesheim, Campus 2-6, 8000 GB Zwolle, The Netherlands (e-mail: cc.vander. maas@windesheim.nl).

Copyright (C) 2015 Wolters Kluwer Health, Inc. All rights reserved.

DOI: $10.1097 /$ AJP.0000000000000320
Key Words: body awareness, chronic pain, multidisciplinary rehabilitation, psychomotor therapy, mediation, catastrophizing, selfefficacy, subgroup

(Clin J Pain 2016;32:763-772)

A lthough multidisciplinary treatment is beneficial for a variety of chronic pain problems, ${ }^{1-3}$ treatment effects are not impressive, and a substantial proportion of patients do not seem to benefit at all. Identification of specific process variables that mediate the effects of treatment on patient outcomes could facilitate development of more effective and efficient therapies. Furthermore, knowledge concerning patient characteristics that moderate effects of treatment could help match certain subgroups of patients with the most appropriate treatments, and tailor interventions to patient characteristics. ${ }^{4}$ Some studies aimed at defining mediators and moderators of chronic pain treatment have been published since Vlaeyen and Morley ${ }^{5}$ stated that this is one of the most important directions of future research related to interventions for chronic pain. Pain catastrophizing and self-efficacy have shown to be mediating factors of treatment outcome in chronic low back pain and temporomandibular disorder, respectively. ${ }^{6-8}$

Recently, we performed a cluster randomized clinical trial (RCT) in which a multidisciplinary rehabilitation treatment with and without psychomotor therapy (PMT) was evaluated. ${ }^{1}$ The multidisciplinary treatment was aimed at improving health-related quality of life (HRQOL) and decreasing pain disability by learning to cope and live with the pain and consisted of several components (ie, occupational therapy, relaxation, graded activity, pain education, rational-emotive therapy, and sports). The treatment period lasted 2 days a week for 12 weeks long. PMT is an experiential treatment that incorporates body awareness (BA) as a primary target of intervention. It uses forms of movement-oriented and body-oriented techniques combined with verbal reflection on self-experiences to teach patients to recognize and understand patterns in physical sensations, feelings, and behavior. ${ }^{9}$ PMT sessions were given once a week for 90 minutes, 10 sessions in total. The RCT demonstrated a significant effect of both active treatments on catastrophizing, self-efficacy, BA, depression, quality of life, and disability. Whether the effects proceeded according to the theoretical assumptions we made (Fig. 1) was not examined. Therefore, the first aim of this study was to examine whether, across treatment conditions, changes in BA are related to improvements in HRQOL, disability, and depression and whether these improvements are mediated 


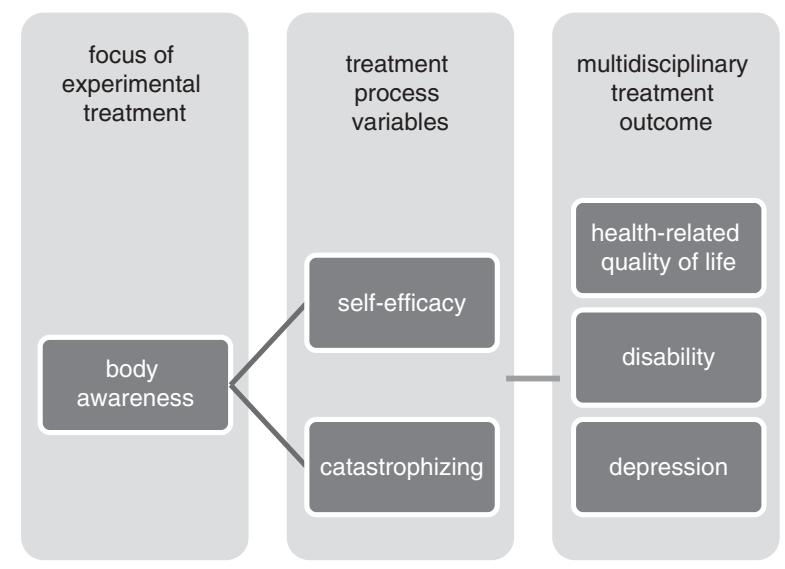

FIGURE 1. Theoretical assumptions of the relations between the different variables.

by self-efficacy and catastrophizing. The RCT also showed that adding PMT led to a significantly larger decrease in depression and catastrophizing and a significantly larger increase in BA compared with the multidisciplinary treatment without PMT. There were no significant differences found in the RCT between treatment as usual (TAU) + PMT and TAU on HRQOL and disability. Although PMT has BA as a primary target of intervention it is not clear whether increased BA is the mechanism of change by which the multidisciplinary treatment with PMT led to greater benefits. Because the added value of PMT was mainly found on depression, we conducted mediation analyses specifically for this outcome. Thus, the second aim of this study was to investigate whether BA is mediating the difference in treatment outcome on depression between a multidisciplinary treatment with and without PMT. In addition, because PMT is specifically aimed at increasing BA, it was hypothesized that especially patients with initially low BA would benefit from this intervention. Therefore, the third aim was to investigate whether a subgroup of patients scoring low on BA showed larger differences in treatment gains in HRQOL, pain disability, depression, pain self-efficacy, pain catastrophizing, and BA in a multidisciplinary treatment with PMT than without PMT.

\section{METHODS}

This study presents a follow-up analysis of an RCT the methods of which have been described elsewhere. ${ }^{1}$ The aim of the RCT was to evaluate short-term and long-term effects on HRQOL, disability, depression, BA, catastrophizing, and self-efficacy in a multidisciplinary pain rehabilitation program with and without PMT.

\section{Participants}

Chronic pain patients were recruited from November 2007 through March 2010. Patients with chronic musculoskeletal pain, who were older than 18 years and were referred to Reade, Centre for Rehabilitation and Rheumatology, in Amsterdam, the Netherlands. They were screened by a physician and a psychologist for eligibility for chronic pain treatment. To be eligible for treatment, the patient's functioning had to be deteriorated because of unexplained musculoskeletal pain that lasted for $>6$ weeks, with social and psychological factors assuming to play an important maintaining role. All patients with an indication for group treatment were asked to participate in the current study. Patients were requested to stop all other treatment for their chronic pain, except pain medication. Of the 114 chronic pain patients who were invited to participate in the study, $20(17.5 \%)$ declined participation. Through cluster randomization, 45 patients received TAU and 49 patients TAU with PMT (PMT). Seventeen patients in TAU and 25 patients in PMT dropped out of the study on different follow-up (FU) moments (posttreatment $\mathrm{TAU}=12$, PMT = 4; 3-mo FU: TAU = 4, PMT = 14; 6-mo FU: $\mathrm{TAU}=2, \mathrm{PMT}=1 ; 12-\mathrm{mo} \mathrm{FU}: \mathrm{TAU}=1$, PMT = 7) for different reasons (ie, discontinued treatment, pregnancy, relapse, other priorities, moved away, and unknown). The baseline data of the complete sample are presented in Table 1.

TABLE 1. Baseline Data of the Patients Randomized to Treatment as Usual (TAU) and Treatment as Usual Plus Psychomotor Therapy (PMT)

\begin{tabular}{|c|c|c|c|}
\hline & $\begin{array}{c}\text { TAU } \\
(n=45)\end{array}$ & $\begin{array}{c}\text { PMT } \\
(n=49)\end{array}$ & $\boldsymbol{P}$ \\
\hline Women $(\%)$ & 71.1 & 91.8 & 0.009 \\
\hline Age (mean [SD]) & $45.4(11.1)$ & $38.6(11.1)$ & 0.004 \\
\hline Marital status (\%) & & & 0.362 \\
\hline Married/living together & 44.5 & 49.0 & \\
\hline Single & 28.9 & 38.8 & \\
\hline Divorced & 13.3 & 4.1 & \\
\hline Other & 13.3 & 8.1 & \\
\hline Education level $(\%)^{*}$ & & & 0.770 \\
\hline Low & 17.8 & 20.4 & \\
\hline Middle & 42.2 & 30.6 & \\
\hline High & 37.7 & 49.0 & \\
\hline Unknown & 2.2 & 0 & \\
\hline Paid work (yes\%) & 13.3 & 16.3 & 0.717 \\
\hline Pain diagnoses $(\%)$ & & & 0.077 \\
\hline Generalized pain $\dagger$ & 24.5 & 16.3 & \\
\hline Joint pain & 4.4 & 8.2 & \\
\hline Neck pain & 17.8 & 38.8 & \\
\hline Back pain & 24.4 & 22.4 & \\
\hline Upper extremities & 17.8 & 10.2 & \\
\hline Others & 11.1 & 4.1 & \\
\hline Pain duration $(\%)$ & & & 0.042 \\
\hline $3 \mathrm{mo}-2 \mathrm{y}$ & 13.3 & 36.8 & \\
\hline $2-5 y$ & 31.1 & 28.6 & \\
\hline$>5 y$ & 55.6 & 34.7 & \\
\hline $\begin{array}{l}\text { Pain intensity (NRS 0-10) } \\
\quad(\text { mean }[\text { SD] }) \S\end{array}$ & $5.78(1.73)$ & $5.51(1.76)$ & 0.459 \\
\hline Depression (mean [SD]) & $18.68(9.00)$ & $20.23(7.85)$ & 0.390 \\
\hline $\begin{array}{l}\text { HRQOL physical component } \\
\text { (mean [SD]) }\end{array}$ & $31.51(7.17)$ & $32.42(6.72)$ & 0.526 \\
\hline $\begin{array}{l}\text { HRQOL mental component } \\
\text { (mean }[\mathrm{SD}])\end{array}$ & $\begin{array}{c}39.59 \\
(12.29)\end{array}$ & $\begin{array}{l}39.89 \\
(10.45)\end{array}$ & 0.899 \\
\hline Disability (mean [SD]) & $\begin{array}{c}40.34 \\
(10.34)\end{array}$ & $40.00(9.00)$ & 0.869 \\
\hline Pain catastrophizing (mean [SD]) & $\begin{array}{l}24.10 \\
(11.53)\end{array}$ & $\begin{array}{l}20.10 \\
(10.21)\end{array}$ & 0.089 \\
\hline Pain self-efficacy (mean [SD]) & $\begin{array}{c}30.70 \\
(10.72)\end{array}$ & $\begin{array}{c}32.77 \\
(10.25)\end{array}$ & 0.351 \\
\hline
\end{tabular}

*Educational level is based on the Dutch school system, where low education is primary school and lower vocational education, middle is mediocre vocational education and higher secondary education and high is higher vocational education and university.

$\dagger$ Including fibromyalgia.

\$Including post whiplash syndrome.

$\S$ Average of least and usual pain.

HRQOL indicates health-related quality of life; NRS, Numeric Rating Scale. 


\section{Procedure}

After screening by the rehabilitation physician and a psychologist and referral to group treatment, the investigator sent an information letter about the study, the questionnaires, and the informed consent to the patient. In the week before or during the first week of treatment the patient had a meeting with the investigator for extra information if needed. Assessments were accomplished 1 week before the start of the treatment (baseline), directly after a 12-week treatment group program (or during the last week of treatment), and at 3,6, and 12-mo FU. At each assessment time, the patient received a set of questionnaires to fill out at home.

\section{Measures}

\section{Treatment Outcome Variables}

HRQOL was measured by the RAND-36 (RAND Health Sciences ${ }^{10}$ ) (Dutch version ${ }^{11}$ ), which is considered to be equal to the worldwide better known SF-36. The RAND-36 is a self-report measure of general health and quality of life, comprising 36 items sorted in 8 categories of health, which can be summarized into 2 component scores. The physical component consists of physical functioning (10 items), role limitations physical (4 items), bodily pain (2 items), and general health perception (5 items). The mental component consists of social functioning ( 2 items), role limitations emotional (3 items), mental health (5 items), and vitality (4 items). One item is added to the questionnaire to measure the perceived health change over the last year. All raw scale scores were summarized and linearly converted to a scale from 0 (poor health) to 100 (excellent health), with higher scores indicating higher levels of functioning or wellbeing.

Disability was measured by the Pain Disability Index ${ }^{12}$ (Dutch version by Pain Management and Research Centre, University Hospital Maastricht, 1999), a 7-item self-report measure of pain-related disability. Ratings are made on an 11-point scale, with higher scores indicating more painrelated disability, with a minimum score of 0 and a maximum score of 70 .

Depression was measured with the Beck Depression Inventory ${ }^{13}$ (Dutch version ${ }^{14}$ ), consisting of 21 items scored on a 4-point Likert scale ranging from 0 to 3 , with 0 indicating absence of the symptom and 3 the worst statement. Higher scores reflect higher levels of depression, with a minimum score of 0 and a maximum score of 63 .

\section{Treatment Process Variables}

The Pain Catastrophizing Scale ${ }^{15}$ (Dutch version ${ }^{16}$ ) is a 13-item self-report measure of the tendency of the patient to engage in catastrophic thinking. Ratings are made on a 5-point scale, with higher scores reflecting more catastrophic thoughts, with a minimum score of 0 and a maximum score of 52 .

The Pain Self-efficacy Questionnaire ${ }^{17}$ (Dutch version $^{18}$ ) is a 10-item self-report measure of pain self-efficacy beliefs. Ratings are made on a 7-point scale, with higher scores reflecting stronger self-efficacy beliefs, with a minimum score of 0 and a maximum score of 60 .

\section{BA}

Effect mediators are variables measured during treatment and indicate the nature or the mechanism of the relationship between treatment and outcome. The putative mediator "BA" is based on theory about the PMT intervention. BA was measured by the Scale of Body Connection, ${ }^{19}$ which was shown to be one of the most psychometrically sound instruments measuring BA. ${ }^{20}$ The Scale of Body Connection is a self-report measurement containing 2 subscales, BA (12 items) and body dissociation (8 items). The original version showed good reliability and validity. ${ }^{19}$ For the purpose of this study, this questionnaire was translated into Dutch and only the subscale "body awareness" was used for analysis. Ratings are made on a 5-point scale, with higher scores reflecting higher BA, with a minimum score of 1 and a maximum score of 5 . In the present study, Cronbach $\alpha$ for the sample at baseline was 0.80 .

\section{Statistical Analyses}

All statistical analyses were carried out according to the intention-to-treat principle. All patients including withdrawal from treatment and patients with poor compliance remained in the group to which they were randomized. Data analyses were performed by linear mixed-model analysis in MLwiN 2.26 (Centre for Multilevel Modelling, University of Bristol, 2012). Three levels were defined, time of measurement (ie, posttreatment, 3, 6, and 12-mo FU) was clustered within patients and patients were clustered within therapy groups (cluster randomization). All analyses in which the treatment conditions were compared were adjusted for age, sex, pain duration, and pain diagnosis due to statistically, clinically relevant differences, or both at baseline between treatment groups on these factors.

\section{Overall Associations and Mediation Effects Across the 2 Conditions}

The theoretically assumed relations between variables (Fig. 1) across treatment conditions were examined by mediation analysis, ${ }^{21}$ using the Baron and Kenny approach with 3 successive linear mixed-regression models. First, the relationship between $\mathrm{BA}$ and the outcome variables was examined with a regression model where the outcome variables were the dependent variables and BA was the independent variable (model 1). Second, the relationship between the process variables, potential mediators, and the outcome variables were examined with a regression model where the outcome variables were the dependent variables and the process variables were the independent variables (model 2). Whether the relationship between BA and the outcome variables was mediated by the process variables was examined by a third regression model where the outcome variable was the dependent variable and BA and the process variable(s) were the independent variables (model $3)$. The proportion of decrease of the regression coefficient (RC) of BA in model 3 compared with model 1 was considered to be the amount of mediation.

\section{Mediation Analysis in Relation to the Difference in Effect Between Treatment Conditions}

Mediation of the difference in treatment effect between the treatment conditions on depression was investigated by 3 linear mixed models. ${ }^{20}$ In the first model, showing the total effect, depression was the dependent variable and treatment and the pretreatment score of depression were the independent variables. In the second model the relation between BA and treatment was examined, with BA as the dependent variable and treatment and the pretreatment 
score of BA as the independent variables. In the third model BA was added as an independent variable. Because the RCT showed a significant difference on depression at posttreatment, only this timepoint was used in the analysis. The proportion of RC decrease in model 3 compared with model 1 was considered to be the amount of mediation, known as the indirect effect.

\section{Subgroup Analyses}

On the basis of the BA scores at pretreatment, the patient group was divided by a median split in subgroups of high and low BA. Multilevel analyses were used to investigate whether there were significant differences overall and at specific timepoints (posttreatment, 3, 6, or 12-mo FU) between treatment conditions in the 2 subgroups. These were post hoc analyses.

\section{RESULTS}

\section{Overall Associations and Mediation Effects Across the 2 Treatment Conditions}

The first model shows that the change over time in BA was significantly related to the change over time in all other variables (Table 2). The second model shows that the change over time in the 2 potential mediators self-efficacy (model 2a) and catastrophizing (model $2 \mathrm{~b}$ ) were related to the change over time in all outcome variables. The third model shows that for HRQOL the significant relationship with BA disappeared when self-efficacy (model 3a) or catastrophizing (model 3b) was added (Table 2). The RC of BA decreased $79 \%$ and $63 \%$ after adding self-efficacy, respectively, catastrophizing to the regression model of the physical component of HRQOL and the RC of BA decreased $73 \%$ and $51 \%$ after adding self-efficacy, respectively, catastrophizing to the regression model of the mental component of HRQOL. This suggests that the relationship between BA and HRQOL is mediated by self-efficacy and catastrophizing. For disability, the significant relationship with BA only disappeared when self-efficacy was added (RC decreased $70 \%$ ), the RC of BA decreased $49 \%$ by adding catastrophizing but remained significant. This seems to suggest that the relationship between $\mathrm{BA}$ and disability is mainly mediated by self-efficacy. Although the RC of BA decreased $55 \%$ and $44 \%$ by adding self-efficacy and catastrophizing, respectively, the relationship between BA and depression remained significant, even when both process variables were added (model $3 \mathrm{c}$ ). This suggests that there are both direct and indirect effects of BA on depression. The longitudinal correlation between self-efficacy and catastrophizing was moderate $(-0.47)$.

\section{Mediation Analysis in Relation to the Difference in Effect Between Treatment Conditions}

In the second set of mediation analyses, we examined whether the difference in treatment effects on depression immediately posttreatment were related to PMT having a more prominent effect on BA than TAU. The first regression model tested the direct effect of treatment condition (ie, PMT vs. TAU) on depression. The RC of treatment condition was $-3.93(95 \%$ confidence interval $[\mathrm{CI}]=$ $-7.11,-0.75)$, indicating a significantly larger effect of PMT on posttreatment depression compared with TAU. In the second regression model the relation between $\mathrm{BA}$ and treatment at posttreatment was examined. The $\mathrm{RC}$ of treatment condition in this model was $0.31(95 \% \mathrm{CI}=0.11$, $0.5)$, indicating a significantly larger effect of PMT on posttreatment BA compared with TAU. In the third regression model, BA was added as the potential mediator. The RC of treatment decreased by $34 \%$ to $-2.59 \%(95 \%$

TABLE 2. Regression Coefficients (RC) and $95 \%$ Confidence Intervals (CI) of the Relationship Between Body Awareness and the Outcome and Process Variables and the Mediation of the Process Variables on the Relationship Between Body Awareness and the Outcome Variables

\begin{tabular}{|c|c|c|c|c|c|}
\hline \multirow{2}{*}{$\begin{array}{l}\text { Dependent } \\
\text { Variables }\end{array}$} & \multirow{2}{*}{$\begin{array}{l}\text { Independent } \\
\text { Variables }\end{array}$} & \multicolumn{4}{|c|}{ RC (95\% CI) } \\
\hline & & Model 1* & Model $2 \mathbf{a} \dagger$ & Model $\mathbf{2 b \dagger}$ & Model 3a \\
\hline$\overline{\text { PCS RAND }}$ & $\begin{array}{c}\text { SBCBA } \\
\text { PSEQ } \\
\text { PCS }\end{array}$ & $2.38(0.57,4.19)$ & $0.25(0.18,0.33)$ & $-0.21(-0.30,-0.13)$ & $\begin{array}{l}0.50(-1.34,2.34) \\
0.26(0.17,0.35)\end{array}$ \\
\hline \multirow{2}{*}{$\begin{array}{l}\text { MCS } \\
\text { RAND }\end{array}$} & SBCBA & $4.99(2.27,7.71)$ & & & $1.35(-1.20,3.90)$ \\
\hline & $\begin{array}{l}\text { PSEQ } \\
\text { PCS }\end{array}$ & & $0.49(0.37,0.60)$ & $-0.49(-0.62,-0.37)$ & $0.51(0.39,0.63)$ \\
\hline PDI & $\begin{array}{l}\text { SBCBA } \\
\text { PSEQ } \\
\text { PCS }\end{array}$ & $-5.46(-8.03,-2.88)$ & $-0.53(-0.64,-0.42)$ & $0.48(0.36,0.60)$ & $\begin{array}{l}-1.66(-4.11,0.78) \\
-0.51(-0.63,-0.40)\end{array}$ \\
\hline BDI & $\begin{array}{l}\text { SBCBA } \\
\text { PSEQ } \\
\text { PCS }\end{array}$ & $-5.69(-7.48,-3.90)$ & $-0.47(-0.54,-0.40)$ & $0.50(0.42,0.59)$ & $\begin{array}{l}-2.57(-4.17,-0.97) \\
-0.43(-0.51,-0.36)\end{array}$ \\
\hline $\begin{array}{l}\text { PSEQ } \\
\text { PCS }\end{array}$ & $\begin{array}{l}\text { SBCBA } \\
\text { SBCBA }\end{array}$ & $\begin{aligned} & 7.41(5.10,9.71) \\
&-5.67(-7.78,-3.56)\end{aligned}$ & & & \\
\hline $\begin{array}{l}\text { *Outcome } \\
\text { †Outcome } \\
\text { †Outcome } \\
\text { variables. } \\
\text { §Sobel test } \\
\text { BDI indica } \\
\text { Pain Catastrop } \\
\text { subscale Body }\end{array}$ & $\begin{array}{l}\text { ocess variable } \\
\text { ble was the d } \\
\text { ble was the d } \\
\text { longitudinal } \\
\text { eck Depressio } \\
\text { g Scale; PCS } \\
\text { reness. }\end{array}$ & $\begin{array}{l}\text { the dependent variable a } \\
\text { lent variable and the proces } \\
\text { dent variable and body aw } \\
\text { sion analysis of multiple m } \\
\text { ventory; MCS RAND: Mer } \\
\text { D: Physical Component S }\end{array}$ & $\begin{array}{l}\text { ody awareness was the in } \\
\text { ariables (PSEQ 2a; PCS } 2 \mathrm{~b} \\
\text { hess and one (PSEQ 3a; P } \\
\text { ation is not possible. } \\
\text { Component Summary of } \\
\text { hary of the RAND-36; PD }\end{array}$ & $\begin{array}{l}\text { endent variable. } \\
\text { vere the independent variabl } \\
\text { 3b) or both process variab } \\
\text { RAND-36; PSEQ: Pain Sel } \\
\text { Pain Disability Index; SBCB }\end{array}$ & $\begin{array}{l}\text { (3c) were the independent } \\
\text { ficacy Questionnaire; PCS: } \\
\text { Scale of Body Connection }\end{array}$ \\
\hline
\end{tabular}


$\mathrm{CI}=-5.67,0.49)$ and was no longer significant. The $P$ value of the Sobel test was 0.14 . This suggests that BA may be at least partially mediating the difference in treatment outcome on depression between a multidisciplinary treatment with and without PMT.

\section{Subgroup Analyses}

Finally, to examine whether patients with initially low BA benefitted more from PMT (compared with TAU) than patients with initially high $\mathrm{BA}$, we divided the patient sample in 2 subgroups by means of median split on pretreatment BA scores. The median for pretreatment BA was 3.42 and grouping resulted in 35 patients (17 TAU, 18 PMT) with low BA and 34 patients (14 TAU, 20 PMT) with high BA at baseline. Patients with high BA demonstrated a significantly lower score on the physical component of HRQOL at baseline than patients with low BA $(t=-2.99$, $P=0.004$ ), whereas no other significant differences between these subgroups were found on patient characteristics, or outcome and process variables at baseline.

Figure 2 visualizes the change over time of the outcome and process variables for the BA subgroups in both treatment groups. Figure 2 shows that, as predicted, especially patients in the low BA subgroup show different changes over time between treatment conditions on most outcome variables, except the physical component of HRQOL. Patients with high BA show overall less pronounced differences between treatment conditions. Table 3 shows the results for the overall treatment condition effects in the low and high BA subgroup for all outcome and process variables. In the low BA subgroup, significant differences between treatment conditions were found on depression $(\mathrm{RC}=-3.28 ; 95 \%$ $\mathrm{CI}=-6.25,-0.32), \mathrm{BA}(\mathrm{RC}=0.37 ; 95 \% \mathrm{CI}=0.16,0.58)$, and pain catastrophizing $(\mathrm{RC}=-6.56 ; 95 \% \mathrm{CI}=-10.94$, -2.18 ). The high BA subgroup showed no significant differences between treatment conditions on any of the process or outcome variables.

Figure 3 shows the differences in the outcome (A) and process variables (B) immediately posttreatment (T1-T0) for the 2 treatment conditions for patients with high and low BA separately. With regard to outcome variables
(Fig. 3A), patients with low BA receiving TAU seem to have the smallest treatment gains overall. Compared with TAU, these patients seem to benefit from PMT especially with regard to the mental component of HRQOL (6.46 points; $\mathrm{RC}=9.06 ; 95 \% \mathrm{CI}=2.21,15.92)$, pain-related disability (5.29 points; not significant), and depression (8.02 points; $\mathrm{RC}=-6.76 ; 95 \% \mathrm{CI}=-10.97,-5.55)$. At 3,6 , or 12-month FU no significant differences between conditions were apparent for any of the outcomes in the low BA subgroup (Table 4). In the high BA subgroup, no significant differences between treatment conditions were found for any of the outcome variables on any timepoint (Table 4). For process variables overall, the largest treatment gains were seen for patients with low BA in the PMT condition (Fig. 3B). Patients with low BA show more improvement on $\mathrm{BA}$ (7.91 points; $\mathrm{RC}=0.42 ; 95 \% \mathrm{CI}=$ $0.13,0.70)$, pain catastrophizing $(7.14$ points; $\mathrm{RC}=-8.11$; $95 \% \mathrm{CI}=-13.22,-3.01)$, and pain self-efficacy $(9.04$ points; $\mathrm{RC}=6.43 ; 95 \% \mathrm{CI}=0.61,12.25)$ after PMT than after TAU. For BA and pain catastrophizing, the benefits of PMT over TAU were maintained until 12 months FU (Table 4). Although Figure 3B suggests that also in the high BA subgroup PMT leads to greater improvement in catastrophizing (6.29 points) and pain self-efficacy (6.38 points), these differences were not significant (Table 4).

\section{DISCUSSION}

BA is a concept under study, with a lack of clarity regarding the definition and contradictory findings about the effect of BA on clinical outcome. In our recently performed $\mathrm{RCT},{ }^{1}$ we defined $\mathrm{BA}$ as a multidimensional construct that involves sensitivity and attentiveness to internal body signals (eg, muscle tension, heartbeat, fluttering in the stomach), overall body states (eg, pain, strained, relaxed) and of the body response to changes in the environment or emotions (eg, acceleration of breath when you become scared or tightening of muscles when someone gets too close to you). ${ }^{19}$ Being more aware of your body is viewed as maladaptive by some, whereas adaptive by others. ${ }^{20,22} \mathrm{~A}$ maladaptive view of $\mathrm{BA}$ is embodied in the concept of

TABLE 2. (Continued)

\begin{tabular}{|c|c|c|c|}
\hline$P$ (Sobel Test) & $\begin{array}{c}\text { RC }(95 \% \text { CI }) \\
\text { Model 3b } \ddagger\end{array}$ & $P$ (Sobel Test) & $\begin{array}{c}\text { RC }(95 \% \text { CI }) \\
\text { Model 3c } \ddagger \S \S\end{array}$ \\
\hline 0.59 & $\begin{array}{c}0.87(-0.98,2.73) \\
-0.22(-0.32,-0.12)\end{array}$ & 0.36 & $\begin{array}{c}-0.05(-1.92,1.82) \\
0.23(0.12,0.33) \\
-0.09(-0.20,0.03)\end{array}$ \\
\hline 0.30 & $\begin{array}{c}2.43(-0.20,5.05) \\
-0.50(-0.64,-0.36)\end{array}$ & 0.08 & $\begin{aligned} 1.10 & (-1.48,3.67) \\
0.33 & (0.18,0.48) \\
- & 0.30(-0.46,-0.15)\end{aligned}$ \\
\hline 0.20 & $-2.76(-5.28,-0.25)$ & 0.04 & $\begin{array}{l}-1.04(-3.48,1.41) \\
-0.40(-0.54,-0.26)\end{array}$ \\
\hline 0.004 & $\begin{array}{c}0.45(0.32,0.59) \\
-3.18(-4.79,-1.58) \\
0.47(0.38,0.56)\end{array}$ & 0.001 & $\begin{aligned} & 0.23(0.07,0.38) \\
- & 2.01(-3.56,-0.45) \\
- & 0.27(-0.36,-0.18) \\
& 0.32(0.22,0.42)\end{aligned}$ \\
\hline
\end{tabular}



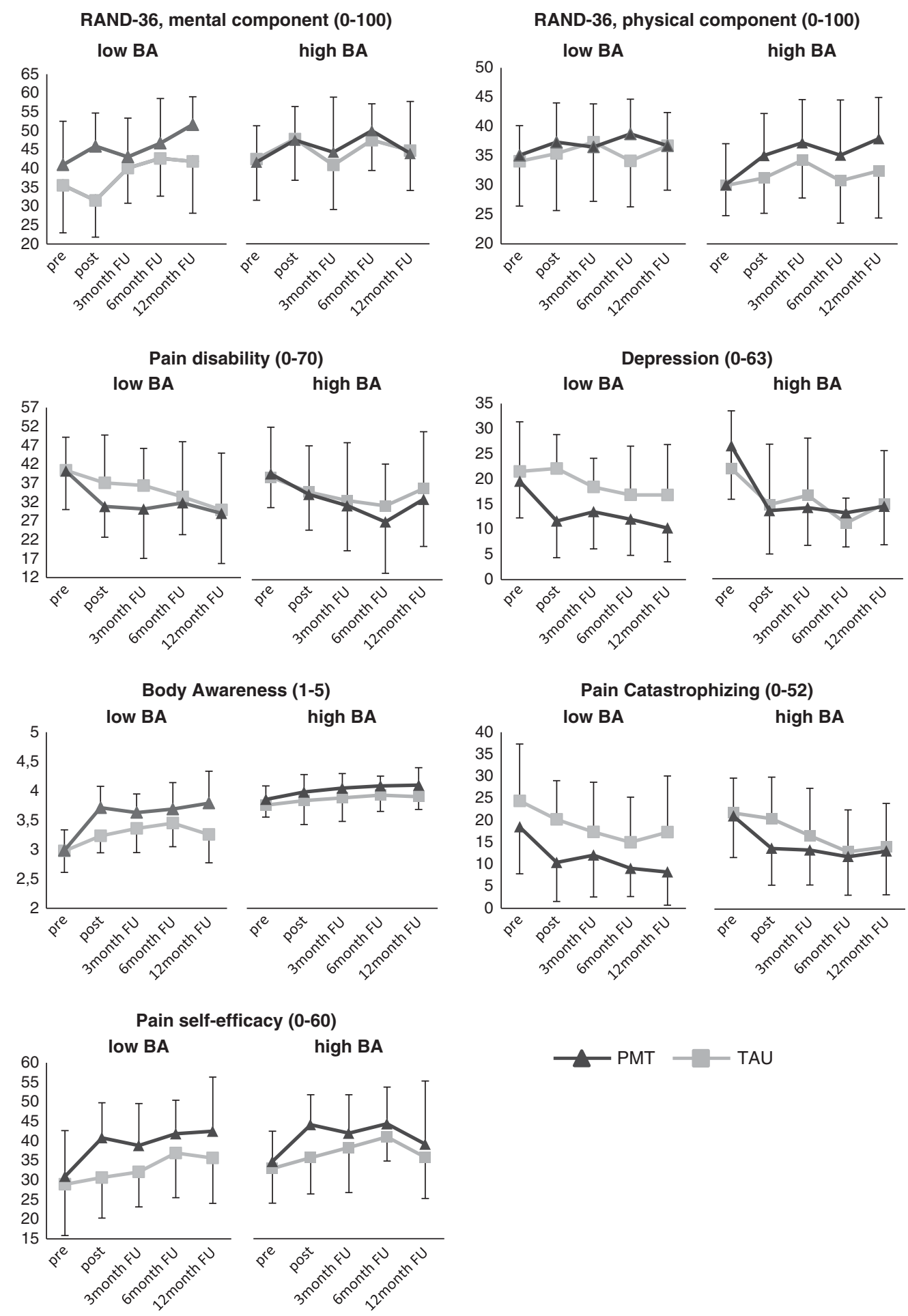

FIGURE 2. Graphic representation of means of outcome and process variables over time for treatment as usual (TAU), treatment as usual with psychomotor therapy (PMT), and subgroups on high and low body awareness (BA). FU indicates follow-up.

hypervigilance, a state in which a patient is constantly scanning his or her body for threatening pain-related sensations, which has a negative impact on pain perception and cognitive functioning. ${ }^{23}$ An adaptive view of BA considers it to be a process allowing a more distant and nonjudgmental perception of internal body signals ${ }^{24}$ or as a state of embodiment, that is, the extent to which a person integrates both the mind and body. ${ }^{20}$ The adaptive view of BA in western society is fairly new and little research has been conducted to link intervention-related changes in BA to clinical outcomes. Therefore, the first aim of this study was to examine our theoretical assumptions concerning the 
TABLE 3. Overall Condition Effects in the Low and High Body Awareness Subgroup

\begin{tabular}{|c|c|c|c|c|}
\hline & \multicolumn{2}{|c|}{ Low Body Awareness (RC [95\% CI]) } & \multicolumn{2}{|c|}{ High Body Awareness (RC [95\% CI]) } \\
\hline & Uncorrected & Corrected* & Uncorrected & Corrected* \\
\hline Disability & $-2.53(-8.37,3.30)$ & $1.03(-3.89,5.95)$ & $-1.80(-7.02,3.42)$ & $2.66(-3.09,8.41)$ \\
\hline PCS RAND & $1.43(-2.28,5.14)$ & $0.01(-3.56,3.57)$ & $2.92(-1.38,7.23)$ & $-2.49(-6.73,1.76)$ \\
\hline MCS RAND & $3.52(-1.23,8.28)$ & $2.39(-2.58,7.36)$ & $1.39(-4.40,7.18)$ & $2.00(-5.21,9.20)$ \\
\hline Depression & $-5.56(-9.04,-2.07) \dagger$ & $-3.28(-6.25,-0.32) \dagger$ & $-1.80(-5.12,1.52)$ & $-1.16(-5.19,2.87)$ \\
\hline Body awareness & $0.36(0.14,0.58) \dagger$ & $0.37(0.16,0.58) \dagger$ & $0.10(-0.09,0.30)$ & $-0.21(-0.44,0.02)$ \\
\hline Pain self-efficacy & $5.79(0.89,10.69) \dagger$ & $3.84(-1.18,8.86)$ & $3.06(-2.75,8.87)$ & $-2.28(-8.85,4.28)$ \\
\hline Pain catastrophizing & $-7.52(-11.89,-3.15) \dagger$ & $-6.56(-10.94,-2.18) \dagger$ & $-3.64(-7.31,0.03)$ & $-3.64(-7.31,0.03)$ \\
\hline
\end{tabular}

* Model corrected for age, sex, pain duration, and pain diagnosis.

$\dagger$ There is a significant difference.

CI indicates confidence interval; MCS RAND: Mental Component Summary of the RAND-36; PCS RAND: Physical Component Summary of the RAND-36; RC, regression coefficient.

relationship between treatment effects on BA and its association with outcome variables, with self-efficacy and pain catastrophizing as potential mediating variables (Fig. 1). The improvement of BA across treatment conditions (PMT and TAU) was significantly associated with an improvement in HRQOL, disability, and depression, this supports the adaptive view of BA. Although improvement in BA was positively related to treatment outcome, the analyses also showed that the relationship between BA and HRQOL, disability and depression was partly mediated by self-efficacy and catastrophizing. The mediating effect of self-efficacy on the relationship between BA and HRQOL and disability shown in this study was expected from a theoretical point of view. A better understanding of body signals is assumed to increase the confidence in one's body and oneself, improving self-efficacy. ${ }^{25} \mathrm{~A}$ stronger self-efficacy is related to better physical functioning 8 and has an enhancing influence on perceived HRQOL. ${ }^{26}$ Another assumption was that by increasing BA, the patient learns to interpret these signals without negative thoughts and concomitant feelings, a more objective interpretation of body signals, thereby decreasing catastrophizing. In this study, an improvement in BA was indeed related to a decrease in catastrophizing, supporting this theoretical assumption. Furthermore, we suggested that catastrophizing could mediate the relationship between BA and HRQOL and
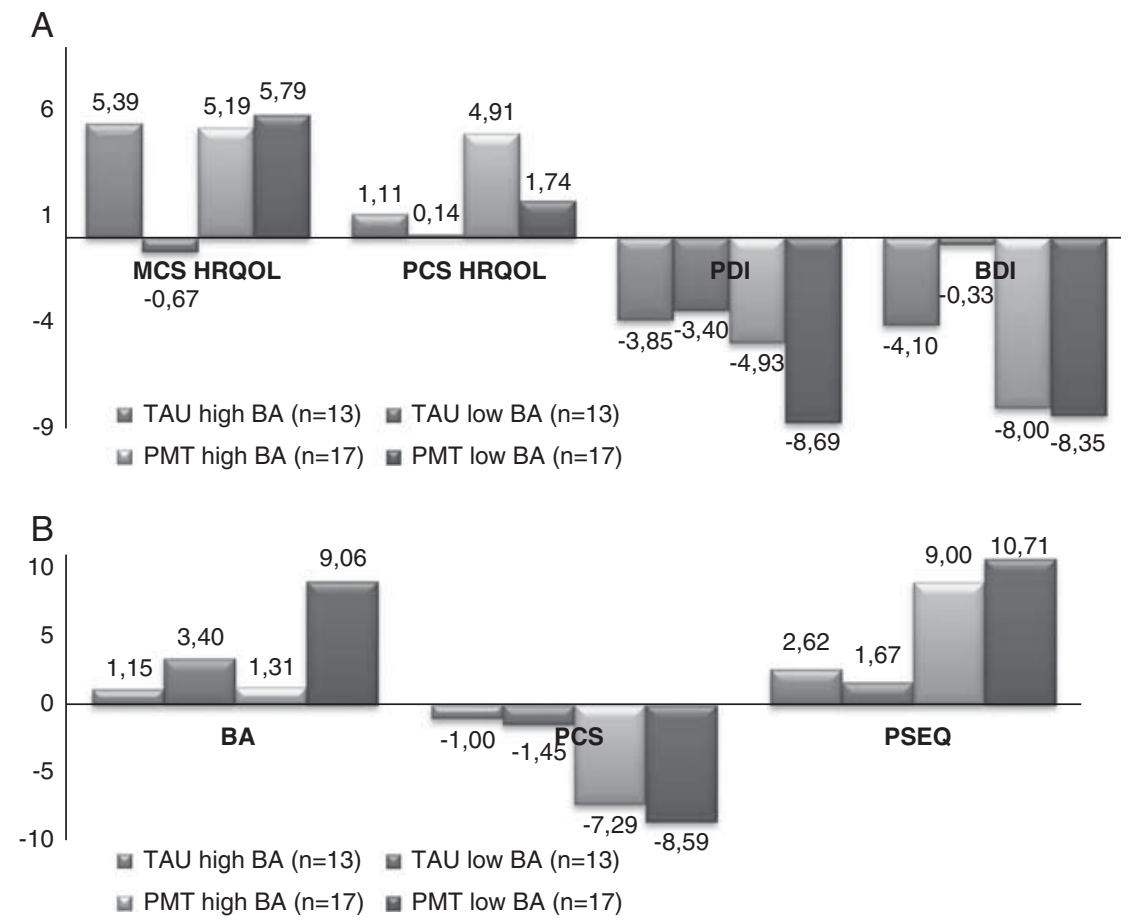

FIGURE 3. Differences in the outcome (A) and process (B) variables (T1-T0) between the 2 treatment conditions for each body awareness subgroup and treatment condition separately. The total score of body awareness (BA) was calculated somewhat different because of visual purposes. The total score was not divided through the amount of items (12). The range of scores for this measurement becomes 12 to 60 instead of 1 to 5. BA indicates scale of body connection subscale body awareness; BDI, Beck Depression Inventory; MCS HRQOL, Mental Component Summary of the RAND-36; PCS, Pain Catastrophizing Scale; PCS HRQOL, Physical Component Summary of the RAND-36; PDI, Pain Disability Index; PMT, treatment as usual with psychomotor therapy; PSEQ, Pain Self-efficacy Questionnaire; TAU, treatment as usual. 
TABLE 4. Results of the Multilevel Analyses Within the Subgroups Low and High Body Awareness at Posttreatment, 3, 6, and 12-month Follow-up (FU)

\begin{tabular}{|c|c|c|c|c|}
\hline & \multicolumn{2}{|c|}{ RC Uncorrected $(95 \%$ CI) } & \multicolumn{2}{|c|}{ RC Corrected $(95 \%$ CI)* } \\
\hline & Low BA & High BA & Low BA & High BA \\
\hline \multicolumn{5}{|l|}{ RAND-36, MCS } \\
\hline Posttreatment & $10.20(3.61,16.79) \dagger$ & $-0.84(-7.93,6.26)$ & $9.06(2.21,15.92) \dagger$ & $-0.30(-8.50,7.91)$ \\
\hline $3 \mathrm{mo} \mathrm{FU}$ & $-1.96(-9.35,5.42)$ & $3.12(-4.59,10.83)$ & $-2.98(-10.57,4.62)$ & $3.61(-5.07,12.29)$ \\
\hline $6 \mathrm{mo} \mathrm{FU}$ & $1.97(-4.80,8.73)$ & $2.74(-6.05,11.53)$ & $0.61(-6.46,7.68)$ & $2.83(-7.04,12.69)$ \\
\hline $12 \mathrm{mo} \mathrm{FU}$ & $5.00(-3.02,13.01)$ & $1.36(-7.08,9.80)$ & $4.09(-4.28,12.08)$ & $1.19(-8.18,10.55)$ \\
\hline \multicolumn{5}{|l|}{ RAND-36, PCS } \\
\hline Posttreatment & $1.24(-3.24,5.73)$ & $3.33(-1.73,8.38)$ & $-0.11(-4.47,4.25)$ & $-1.97(-6.93,3.00)$ \\
\hline $3 \mathrm{mo} \mathrm{FU}$ & $0.20(-4.72,5.11)$ & $2.04(-3.37,7.46)$ & $-1.29(-6.07,3.49)$ & $-3.20(-8.44,2.05)$ \\
\hline $6 \mathrm{mo} \mathrm{FU}$ & $3.40(-1.22,8.01)$ & $1.07(-4.96,7.09)$ & $1.98(-2.54,6.49)$ & $-4.34(-10.30,1.63)$ \\
\hline $12 \mathrm{mo} \mathrm{FU}$ & $0.52(-4.70,5.73)$ & $4.86(-0.97,10.69)$ & $-0.86(-5.93,4.20)$ & $-0.55(-6.21,5.12)$ \\
\hline \multicolumn{5}{|l|}{ PDI } \\
\hline Posttreatment & $-5.26(-12.81,2.28)$ & $0.04(-6.34,6.42)$ & $-1.89(-8.75,4.97)$ & $4.23(-2.72,11.17)$ \\
\hline $3 \mathrm{mo} \mathrm{FU}$ & $-4.64(-12.61,3.33)$ & $-0.75(-7.74,6.23)$ & $-1.08(-8.45,6.30)$ & $3.61(-3.77,10.99)$ \\
\hline $6 \mathrm{mo} \mathrm{FU}$ & $-0.80(-8.27,6.67)$ & $-1.54(-9.20,6.12)$ & $3.29(-3.62,10.19)$ & $3.50(-4.61,11.61)$ \\
\hline $12 \mathrm{mo} \mathrm{FU}$ & $-0.77(-9.25,7.71)$ & $-6.17(-13.56,1.21)$ & $2.99(-4.84,10.82)$ & $-0.87(-8.55,6.82)$ \\
\hline \multicolumn{5}{|l|}{ BDI } \\
\hline Posttreatment & $-9.02(-13.60,-4.44) \dagger$ & $-2.31(-6.44,1.81)$ & $-6.76(-10.97,-5.55) \dagger$ & $-1.55(-6.20,3.11)$ \\
\hline $3 \mathrm{mo} \mathrm{FU}$ & $-3.57(-8.32,1.18)$ & $-2.89(-7.09,1.30)$ & $-1.42(-5.83,2.99)$ & $-2.10(-6.80,2.60)$ \\
\hline $6 \mathrm{mo} \mathrm{FU}$ & $-4.52(-9.00,-0.03) \dagger$ & $0.94(-3.76,5.64)$ & $-1.91(-6.08,2.26)$ & $2.03(-3.24,7.30)$ \\
\hline $12 \mathrm{mo} \mathrm{FU}$ & $-5.89(-10.92,-0.86) \dagger$ & $-0.89(-5.51,3.74)$ & $-3.64(-8.28,1.00)$ & $0.27(-4.84,5.38)$ \\
\hline \multicolumn{5}{|l|}{ SBCBA } \\
\hline Posttreatment & $0.42(0.13,0.71) \dagger$ & $0.07(-0.16,0.29)$ & $0.42(0.13,0.70) \dagger$ & $-0.06(-0.32,0.20)$ \\
\hline $3 \mathrm{mo} \mathrm{FU}$ & $0.30(-0.02,0.62)$ & $0.11(-0.13,0.34)$ & $0.31(0.00,0.62) \dagger$ & $-0.02(-0.29,0.24)$ \\
\hline $6 \mathrm{mo} \mathrm{FU}$ & $0.28(-0.01,0.57)$ & $0.12(-0.14,0.38)$ & $0.28(-0.01,0.57)$ & $-0.01(-0.30,0.28)$ \\
\hline $12 \mathrm{mo} \mathrm{FU}$ & $0.48(0.16,0.81) \dagger$ & $0.20(-0.06,0.46)$ & $0.50(0.18,0.81) \dagger$ & $0.07(-0.22,0.36)$ \\
\hline \multicolumn{5}{|l|}{ PSEQ } \\
\hline Posttreatment & $8.35(2.61,14.1) \dagger$ & $5.67(-0.75,12.10)$ & $6.43(0.61,12.25) \dagger$ & $0.32(-6.66,7.30)$ \\
\hline 3 mo FU & $5.80(-0.35,11.95)$ & $0.91(-5.92,7.73)$ & $3.89(-2.31,10.10)$ & $-4.52(-11.83,2.79)$ \\
\hline $6 \mathrm{mo} \mathrm{FU}$ & $4.42(-1.39,10.23)$ & $-1.65(-9.00,5.69)$ & $2.37(-3.55,8.30)$ & $-7.42(-15.31,0.47)$ \\
\hline $12 \mathrm{mo} \mathrm{FU}$ & $4.29(-2.20,10.77)$ & $3.69(-3.43,10.82)$ & $2.42(-4.10,8.94)$ & $-2.27(-9.82,5.27)$ \\
\hline \multicolumn{5}{|l|}{ PCS } \\
\hline Posttreatment & $-9.15(-14.28,-4.02) \dagger$ & $-5.67(-0.75,12.10)$ & $-8.11(-13.22,-3.01) \dagger$ & $-2.81(-7.89,2.26)$ \\
\hline $3 \mathrm{mo} \mathrm{FU}$ & $-6.09(-11.63,-0.55) \dagger$ & $-3.65(-8.27,0.98)$ & $-5.15(-10.65,0.34)$ & $-1.06(-6.11,3.99)$ \\
\hline $6 \mathrm{mo} \mathrm{FU}$ & $-7.62(-12.88,-2.35) \dagger$ & $-2.25(-7.49,2.99)$ & $-6.46(-11.75,-1.18) \dagger$ & $0.72(-5.07,6.50)$ \\
\hline $12 \mathrm{mo} \mathrm{FU}$ & $-7.60(-13.49,-1.71) \dagger$ & $-2.28(-7.42,2.87)$ & $-6.93(-12.82,-1.04) \dagger$ & $0.78(-4.80,6.35)$ \\
\hline
\end{tabular}

* Model corrected for age, sex, pain duration, and pain diagnosis.

$\dagger$ Significant difference between treatment conditions.

BA indicates body awareness; BDI, Beck Depression Inventory; CI, confidence interval; PCS, Pain Catastrophizing Scale; PDI, Pain Disability Index; PSEQ, Pain Self-efficacy Questionnaire; RAND-36 MCS, Mental Component Summary of the RAND-36; RC, regression coefficient; SBCBA, Scale of Body Connection subscale Body Awareness.

disability. This assumption was based on the findings that a decrease in catastrophizing is related to a decrease in disability $^{27}$ and high catastrophizing is associated with low HRQOL. ${ }^{28}$ In this study, we showed a mediating effect of catastrophizing on the relationship between BA and HRQOL. However, although the RC of BA reduced by $49 \%$ by adding catastrophizing, the association between changes in BA and disability remained significant. This suggests that although a substantial part of the relationship between BA and disability is mediated by catastrophizing it still has an independent part in this relationship as well, which disappears when self-efficacy is added as well. In this study it was also shown that a substantial part of the relationship between improved BA and a decreased level of depression was mediated by self-efficacy and catastrophizing. However, BA still had an independent part in this relationship as well, even when both self-efficacy and catastrophizing were added. This finding is in accordance with the theory that awareness of internal body signals associated with emotions is a key element for affect regulation and for the sense of self. ${ }^{20}$ Furthermore, Ginzburg et $\mathrm{al}^{22}$ found that low sensitivity for internal body signals in combination with high monitoring and high catastrophizing was related to a higher anxiety level than high sensitivity for internal body signals and high monitoring and high catastrophizing, suggesting a relationship between sensitivity for internal body signals and affect regulation. This was a first study to explore the possible relation between BA and outcome variables. A possibility for further research would be prospective mediation, that is, whether early changes in BA, Pain Catastrophizing Scale, and Pain Self-efficacy Questionnaire predict subsequent changes in outcome variables at a later stage. The second aim was to determine whether BA was a mediating factor in the difference in the outcome on depression between a multidisciplinary treatment for chronic pain patients with and without PMT. Mediation analysis showed that BA was a partial mediating factor explaining $34 \%$ of the difference in treatment outcome on depression. Mediation analyses were performed on the difference between the treatment conditions. The clinical care setting of the study did not allow for an inactive control group. Therefore, we could assess the mechanism of action 
only by comparing PMT to TAU and not to an inactive control. Because there were no significant differences between treatment on any of the other measurement points we only assessed mediation for the posttreatment assessment. However, this first exploration indicates that BA might be one of the mechanisms through which PMT works as was hypothesized and justifies further research exploring $\mathrm{BA}$ as one of the working mechanism of PMT. Finally, we hypothesized that because PMT is specifically aimed at increasing BA, patients with a low BA would benefit more from adding PMT to a multidisciplinary treatment than patients with high BA. Significant differences between PMT and TAU were found in the low BA group for the mental component of HRQOL, depression, BA, catastrophizing, and self-efficacy. Patients with high BA did not benefit from extra PMT. This suggests that adding PMT to a multidisciplinary treatment could be beneficial for patients with low BA especially on psychological factors.

The importance of taking the heterogeneity of the chronic pain population into account and matching treatment to certain patient-specific factors has repeatedly been stressed. However, only little research has been performed where a priori patients have been matched to specific treatment protocols according to their patient-specific factors. One example of a treatment focusing on a specific patient characteristic is graded in vivo exposure, where fear of movement/(re)injury is the target of intervention. Indeed, this treatment has demonstrated promising results on several pain-related outcomes in chronic low back pain patients with high fear of movement. ${ }^{29}$ Another example of a focused treatment is behavioral graded activity. The main objective of this treatment is to realize a more active lifestyle, and therefore one may expect that especially patients with a relative low level of physical functioning benefit from this treatment. ${ }^{30}$ Veenhof et $\mathrm{al}^{30}$ found that indeed compared with usual care, behavioral graded activity was the preferred treatment in patients with a low level of physical functioning leading to more improvement in pain intensity, physical activity, and patient perceived assessment. These examples and the results from the present study support the importance of treatment matching to specific patient characteristics. Nevertheless, the results of the present study regarding the BA subgroups analyses should be interpreted with caution because sample size was small. Because of the small sample size it was not feasible to examine moderation with an interaction analysis. However, this first exploration may stimulate further research in this area.

\section{Limitations}

Some limitations should be mentioned about this study. First, 12 patients in the TAU group and 4 patients in the PMT group did not complete their posttreatment questionnaires, yielding a total dropout of $45 \%$. However, longitudinal mixed-model analysis, the method used in this study, uses all information of every person with only $1 \mathrm{FU}$ measurement. It has been demonstrated that this method is even better than multiple imputation techniques. ${ }^{31}$ Therefore, we expect that the chance of bias caused by the total dropout was reduced in the mediation analysis across the 2 treatment conditions. Second, because randomization was not fully successful we needed to perform analyses with adjustments for 4 variables, resulting in a relatively large number of independent variables in light of the sample size. Therefore, the results of this study should be interpreted with caution.
In conclusion, BA may potentially be an important target of treatment that could improve multidisciplinary treatment outcomes in patients with chronic pain. Furthermore, PMT seems to be an intervention that works through BA and which may be especially beneficial for patients with low BA.

\section{REFERENCES}

1. Van der Maas LC, Köke A, Pont M, et al. Improving the multidisciplinary treatment of chronic pain by stimulating body awareness: a cluster-randomized trial. Clin J Pain. 2014; 31:660-669.

2. Hauser W, Bernardy K, Arnold B, et al. Efficacy of multicomponent treatment in fibromyalgia syndrome: a meta-analysis of randomized controlled clinical trials. Arthritis Rheum-Arthritis Care Res. 2009;61:216-224.

3. Carnes D, Homer KE, Miles CL, et al. Effective delivery styles and content for self-management interventions for chronic musculoskeletal pain: a systematic literature review. Clin $J$ Pain. 2012;28:344-354.

4. Turk DC. The potential of treatment matching for subgroups of patients with chronic pain: Lumping versus splitting. Clin $J$ Pain. 2005;21:44-55.

5. Vlaeyen JWS, Morley S. Cognitive-behavioral treatments for chronic pain: what works for whom? Clin J Pain. 2005;21:1-8.

6. Smeets RJEM, Vlaeyen JWS, Kester ADM, et al. Reduction of pain catastrophizing mediates the outcome of both physical and cognitive-behavioral treatment in chronic low back pain. $J$ Pain. 2006; 7:261-271

7. Turner JA, Holtzman S, Mancl L. Mediators, moderators, and predictors of therapeutic change in cognitive-behavioral therapy for chronic pain. Pain. 2007;127:276-286.

8. Miles CL, Pincus T, Carnes D, et al. Can we identify how programmes aimed at promoting self-management in musculoskeletal pain work and who benefits? A systematic review of sub-group analysis within RCTs. Eur J Pain. 2011;15: 775.e1-775.e11.

9. Probst M, Knapen J, Poot G, et al. Psychomotor therapy and psychiatry: what's in the name? Open Compl Med J. 2010;2: 105-113.

10. Program RHS. RAND 36-Item Health Survey 10. Santa Monica, CA: RAND; 1992.

11. Van der Zee KI, Sanderman R, Heyink JW, et al. Psychometric qualities of the RAND 36-item health survey 1.0: a multidimensional measure of general health status. J Behav Med. 1996;3:104-122.

12. Pollard CA. Preliminary validity study of the Pain Disability Index. Percept Mot Skills. 1984;59:974.

13. Beck AT, Erbaugh J, Ward $\mathrm{CH}$, et al. An inventory for measuring depression. Arch Gen Psychiatry. 1961;4:561-571.

14. Bosscher RJ, Koning H, Van Meurs R. Reliability and validity of the Beck Depression Inventory in a Dutch college population. Psychol Rep. 1986;58:696-698.

15. Sullivan MJL, Bishop SR, Pivik J. The Pain Catastrophizing Scale: Development and validation. American Psychological Assn; 1995;7:524-532.

16. Van Damme S, Crombez G, Bijttebier P, et al. A confirmatory factor analysis of the Pain Catastrophizing Scale: invariant factor structure across clinical and non-clinical populations. Pain. 2002;96:319-324.

17. Nicholas MK. The Pain Self-Efficacy Questionnaire: taking pain into account. Eur J Pain. 2007;11:153-163.

18. Van der Maas LCC, de Vet HCW, Köke A, et al. Psychometric properties of the Pain Self-Efficacy Questionnaire (PSEQ): validation, prediction, and discrimination quality of the Dutch version. Eur J Psychol Assess. 2012;28:68-75.

19. Price CJ, Thompson EA. Measuring dimensions of body connection: body awareness and bodily dissociation. J Altern Complement Med. 2007;13:945-954. 
20. Mehling WE, Gopisetty V, Daubenmier J, et al. Body awareness: construct and self-report measures. PLoS One. 2009;4:e5614.

21. Baron RM, Kenny DA. The moderator mediater variable distinction in social psychological research: conceptual, strategic, and statistical considerations. J Pers Soc Psychol. 1986;51: 1173-1182.

22. Ginzburg K, Tsur N, Barak-Nahum A, et al. Body awareness: differentiating between sensitivity to and monitoring of bodily signals. J Behav Med. 2014;37:564-575.

23. Eccleston C, Crombez G, Aldrich S, et al. Attention and somatic awareness in chronic pain. Pain. 1997;72:209-215.

24. Schaefer M, Egloff B, Witthoeft M. Is interoceptive awareness really altered in somatoform disorders? Testing competing theories with two paradigms of heartbeat perception. J Abnorm Psychol. 2012;121:719-724.

25. Landsman-Dijkstra JJA, van Wijck R, Groothoff JW. The long-term lasting effectiveness on self-efficacy, attribution style, expression of emotions and quality of life of a body awareness program for chronic a-specific psychosomatic symptoms. Patient Educ Couns. 2006;60:66-79.
26. Börsbo B, Gerdle B, Peolsson M. Impact of the interaction between self-efficacy, symptoms and catastrophising on disability, quality of life and health in with chronic pain patients. Disabil Rehabil. 2010;32:1387-1396.

27. Quartana PJ, Campbell CM, Edwards RR. Pain catastrophizing: a critical review. Expert Rev Neurother. 2009;9:745-758.

28. Lamé IE, Peters ML, Vlaeyen JWS, et al. Quality of life in chronic pain is more associated with beliefs about pain, than with pain intensity. Eur J Pain. 2005;9:15-24.

29. Woods MP, Asmundson GJG. Evaluating the efficacy of graded in vivo exposure for the treatment of fear in patients with chronic back pain: a randomized controlled clinical trial. Pain. 2008;136:271-280.

30. Veenhof C, Van den Ende CHM, Dekker J, et al. Which patients with osteoarthritis of hip and/or knee benefit most from behavioral graded activity? Int J Behav Med. 2007;14: 86-91.

31. Twisk $\mathbf{J}$, de Boer $\mathbf{M}$, de Vente $\mathbf{W}$, et al. Multiple imputation of missing values was not necessary before performing a longitudinal mixed-model analysis. J Clin Epidemiol. 2013;66:1022-1028. 